\title{
Air-fluid level in emphysematous bullae
}

\author{
Hajime OSAWA ${ }^{1}$ \\ Shinichiro OKAUCHI \\ Hiroaki SATOH $^{1}$
}

\author{
${ }^{1}$ Tsukuba Üniversitesi Mito Tıp Merkezi, Göğüs Hastalıkları Bölümü, \\ Mito, Japonya \\ ${ }^{1}$ Department of Respiratory Medicine, Mito Medical Center, Tsukuba \\ University, Mito, Japan
}

Cite this article as: Osawa $\mathrm{H}$, Okauchi S, Satoh $\mathrm{H}$. Air-fluid level in emphysematous bullae. Tuberk Toraks 2019;67(3):234-5.

\section{Yazışma Adresi (Address for Correspondence)}

Dr. Hiroaki SATOH

Department of Respiratory Medicine,

Mito Medical Center, Tsukuba University,

Miya-machi 3-2-7, MITO - JAPAN

e-mail: hirosato@tsukuba.ac.jp

CCopyright 2019 by Tuberculosis and Thorax.

Available on-line at www.tuberktoraks.org.com
To the Editor,

A 73-year-old male presented to our hospital with a two-week history of bloody sputum. At the age of 66-year-old, the patient was diagnosed as having severe chronic obstructive pulmonary diseases, respiratory function test performed two years before revealed forced expiratory volume in one second $18 \%$ predicted. On admission the patient was cachectic. The temperature was $37^{\circ} \mathrm{C}$; pulse, 92 beats per minute; respirations, 18 breaths per minute; and BP 136/82 $\mathrm{mmHg}$. Breath sounds were diminished over the both anterior and lateral areas of the chest. With the patient breathing $2 \mathrm{~L}$ of oxygen by nasal cannula, the saturation level was $95 \%$. The WBC count was 6600 cells $/ \mathrm{mL}$ with $59 \%$ neutrophils, $28 \%$ lymphocytes, $2 \%$ band cells, and $10 \%$ mononuclear cells. Serum C-reactive protein (CRP) level was $1.26 \mathrm{mg} / \mathrm{dL}$. The hemoglobin value was $11.2 \mathrm{~g} / \mathrm{L}$, and the platelet count was 251.000 cell $\mathrm{s} / \mathrm{mL}$. The BUN level was 17 $\mathrm{mg} / \mathrm{dL}$, and the creatinine value was $0.77 \mathrm{mg} / \mathrm{dL}$, respectively. Electrolyte levels, liver tests, and coagulation studies were within normal limits. Serum aspergillus antigen was positive. The admission chest computed tomography (CT) scan demonstrated an air-fluid level within emphysematous bulla in the right lower lobe (Figure 1), which was not found in the emphysematous bulla in chest CT scan taken one year previously. Sputum cultures yielded no pathogenic microorganism. Bronchoscopy and percutaneous needle aspiration were not performed as the respiratory state and general condition of the patient was very poor. Despite the presence of blood sputum and deterioration of respiratory condition, there was 

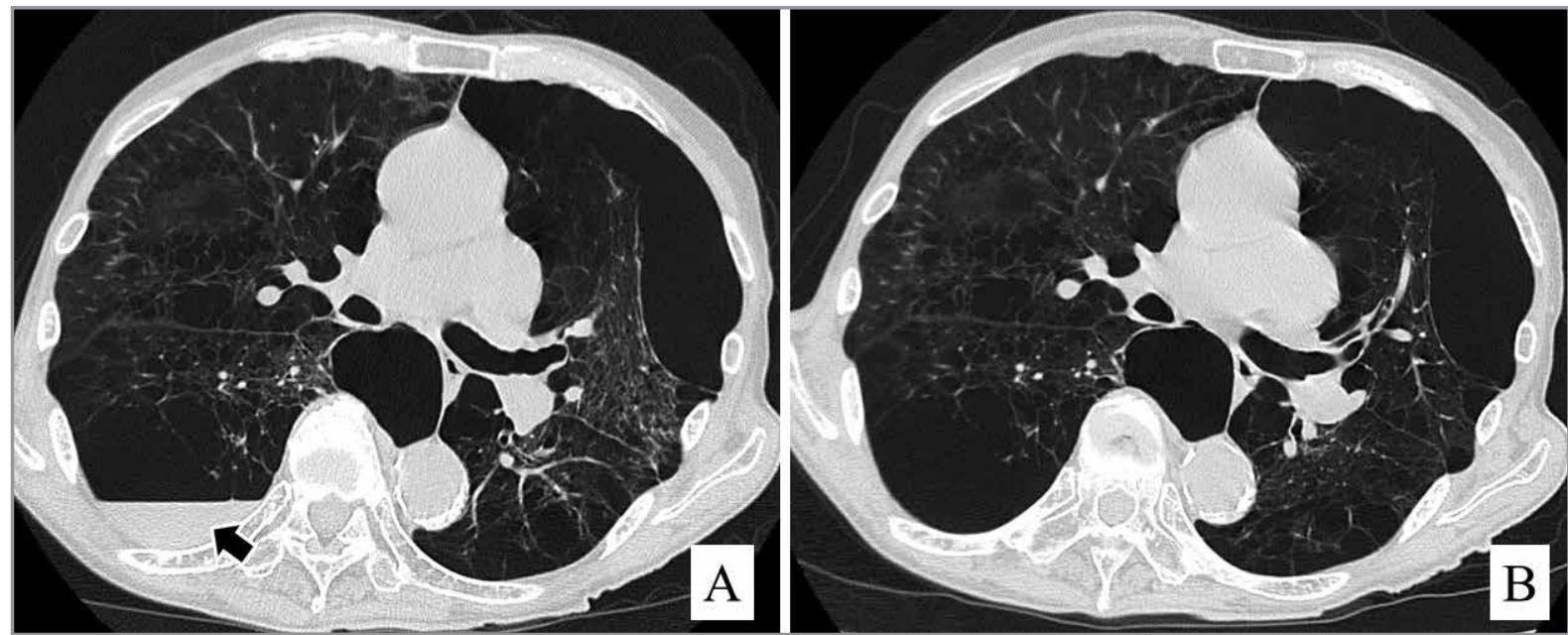

Figure 1. The admission chest CT scan demonstrated an air-fluid level within emphysematous bulla (arrow) in the right lower lobe (A). Disappearance of the air-fluid level within emphysematous bulla was observed on chest CT scan two months after the initiation of the antifungal therapy (B).

neither leukocytosis nor elevated serum level of CRP. Therefore, the existence of infection other than bacterial infection and hemorrhage into the bulla was suspected. The patient did not receive corticosteroid and he had no comorbid malignant disease. In the chest image, it was not a characteristic finding of Pneumocystis or cytomegalovirus infection. Considering this situation, fungal infection was most doubtful, therefore, administration of liposomal-amphotericin B (L-AMB), an antifungal drug, was started. When administration of L-AMB $(2.5 \mathrm{mg} / \mathrm{kg} /$ day $)$ was started, rapid and complete disappearance of symptoms. Disappearance of air-fluid level within emphysematous bulla in the right lower lobe was observed on chest CT scan two months after the initiation of the antifungal therapy (Figure 1B). The patient was administered L-AMB for 21 days. Thereafter, the patient received no additional antimicrobial drug, but he is free of disease 13 months after the completion of L-AMB therapy.

This patient had symptoms with bloody sputum, deterioration of dyspnea, and fever with slight elevation of serum CRP. Chest CT showed no shadow adjacent to the fluid-containing emphysematous bullae. As respiratory condition was poor, bronchoscopy and percutaneous biopsy. Since beta-D glucan showed abnormal value, antifungal drug was administered. Symptoms, images, and laboratory data improved by hospitalization rest, oxygen administration, antifungal medication within a few days. Patients with fluid-containing emphysematous bullae present with a spectrum of illness varying from an absence of symptoms to the presence of symptoms and a severe lung infection (1). A majority of patients, however, are symptomatic without a severe infection, one as observed in the present case. Pathogenesis of fluid-containing emphysematous bullae included infections and diseases other than infectious diseases (1-3). Even in patients with infectious pathogenesis, it is unclear whether the infection arises from the surrounding lung parenchyma or via haematogenous spread. For patients with severe respiratory and general condition, complications may be fatal and bronchoscopic and percutaneous biopsy had better be avoided (1). For symptomatic patients, antimicrobial treatment appears beneficial, but management decisions be tailored to the acuity of presentation.

\section{REFERENCES}

1. Chandra D, Rose $S R$, Carter RB, Musher DM, Hamill RJ. Fluid-containing emphysematous bullae: a spectrum of illness. Eur Respir J 2008;32:303-6.

2. Henao-Martinez AF, Fernandez JF, Adams SG, Restrepo C. Lung bullae with air-fluid levels: what is the appropriate therapeutic approach? Respir Care 2012;57:642-5.

3. Thomas DW, Balikai G, Nokes TJ. Bleeding into an emphysematous bulla. Br I Haematol 2008;141:1. 